\title{
MARCO FILOSÓFICO DEL COMPROMISO ORGANIZACIONAL: DISCUSIÓN DEL MODELO DE ALLEN \& MEYER, Y PROPUESTA DE UN NUEVO MODELO DE ESTUDIO
}

\section{PHILOSOPHICAL FRAMEWORK FOR THE ORGANIZATIONAL COMMITMENT: DISCUSSION OF THE ALLEN \& MEYER MODEL AND PROPOSAL OF A NEW MODEL OF STUDY}

Santiago Ávila Vila (EAE Business School) ${ }^{1}$

Marcelo Pascual Faura (Universidad CEU San Pablo) ${ }^{2}$

\section{Resumen:}

El objetivo de este trabajo se centra en la discusión y propuesta de un nuevo modelo de estudio del Compromiso Organizacional, ya que una investigación tan fragmentada como la actual, derivada de la diversidad de modelos que se han sucedido desde los inicios de su estudio (Becker, 1960), ha generado una gran confusión. Confusión, que ha sido alimentada también por los especialistas en análisis factorial, al centrarse en exceso en la interpretación matemática de sus resultados y olvidar la naturaleza misma de la medida. Circunstancias que justifican: a) el desarrollo de un marco filosófico del Compromiso Organizacional, que le dé soporte desde una doble perspectiva: la del trabajador, y la de la organización en función del estilo de liderazgo con que se emplea su dirección; b) la discusión, en base al marco referido, de la propuesta tridimensional de Allen y Meyer (1990), ya que como ha quedado suficientemente demostrado en diversas investigaciones (Bergman, 2006; Cohen, 2003; Jong-Wook, Price, \& Mueller, 1997; Solinger, Van Olffen, y Roe, 2008), no todas sus dimensiones miden este tipo de compromiso; c) la concreción de la propuesta misma, basada en la investigación empírica realizada a tal fin, de un nuevo modelo de estudio que sirva de guía a la parte empírica de las investigaciones futuras. El presente trabajo, propone un nuevo modelo de Compromiso Organizacional, que lo define como un constructo de una sola dimensión de carácter afectivo, que viene moderada por la concepción ética del trabajador.

Palabras clave: Marco Filosófico del Compromiso Organizacional, Modelo de Compromiso Organizacional, Compromiso Afectivo, Percepción de las Políticas de Recursos Humanos.

Códigos JEL: J24, M12, D23, M54.

\section{Abstract:}

The objective of this paper is to discuss and propose a new model for the study of the Organizational Commitment, since such a fragmented research as the current one, derived from the diversity of models that have followed each other since the beginning of its study (Becker, 1960), has generated a great deal of confusion. Confusion, which has also been increased by specialists in factorial analysis, by focusing too much on the mathematical interpretation of their results and forgetting the very nature of measurement. Circumstances that justify: a) the

\footnotetext{
1 savila@eae.es, EAE Business School.

2 mpascualfaura@gmail.com, Universidad CEU San Pablo.

Recibido 18 de octubre de 2019. Aceptado 18 de mayo de 2020.
} 
development of a philosophical framework for the Organizational Commitment, which supports it from a double perspective: that of the worker, and that of the organization according to the leadership style that is used by management; $\mathrm{b}$ ) the discussion, based on the referred framework, of the three-dimensional proposal of Allen \& Meyer (1990), since as it has been sufficiently demonstrated in diverse investigations (Bergman, 2006; Cohen, 2003; Jong-Wook, Price, \& Mueller, 1997; Solinger, Van Olffen, \& Roe, 2008), not all its dimensions measure this type of commitment; c) the concretion of the proposal itself, based on the empirical research carried out to that end, of a new study model that serves as a guide to the empirical part of the future research. The present work proposes a new model of Organizational Commitment, which defines it as a construct of a single dimension of an affective nature, which is moderated by the ethical conception of the worker.

Key words: Philosophical Framework for the Organizational Commitment, Organizational Commitment Model, Affective Commitment, Perception of Human Resources Policies.

JEL Codes: J24, M12, D23, M54.

\section{INTRODUCCIÓN}

Los cambios evocados en todos los ámbitos de la sociedad por las denominadas nuevas tecnologías desde finales del siglo XX, han propiciado que las empresas dirijan su interés hacia el Compromiso Organizacional de los trabajadores, ya que sus órganos de dirección han tomado conciencia de que así podrán disponer de una fuerza laboral más eficiente y productiva (González et al., 2014; Klein, 2016).

Muchos directivos, se plantean cómo incrementar este tipo de compromiso ya que favorece una reducción de las tasas de absentismo y rotación, y por ende, la reducción de los costes directos e indirectos consecuentes, además de procurar una mejora significativa en el nivel de atención al cliente (Apascaritei y Elvira, 2018; Vecina y Chacón, 2013).

La constante atención de las organizaciones a los resultados a corto plazo, ha trasladado una enorme presión sobre sus directivos para cumplir con los objetivos marcados. Directivos, que al no poder incrementar los ingresos de sus compañías, se han centrado en recortar sus plantillas para aumentar beneficios, lo que finalmente se ha concretado en un declive del Compromiso Organizacional por parte de los trabajadores (Branham, 2005).

Como consecuencia, la desconfianza se ha instalado tanto en las relaciones sociales como laborales, y como ya anunciara Bauman (2004) a principios de este siglo, los compromisos del tipo "hasta que la muerte nos separe" han sido sustituidos por los de "permanecer en la empresa mientras se esté satisfecho", y en el peor de los casos hasta la próxima reestructuración. Circunstancias todas que evidenciarían la necesidad, anunciada ya a finales del pasado siglo por Mowday et al. (1982), de trabajar sobre una actitud que favorece el hecho de que las personas se muestren dispuestas al logro organizativo y a la continuidad en la empresa, o lo que es lo mismo, el Compromiso Organizacional.

No obstante, una investigación tan fragmentada como la actual (Mercurio, 2015), que lo ha definido, entre otras formas, como:

- Una única fuerza de carácter económico (Becker, 1960), o afectivo (Mowday et al., 1974; Mowday et al., 1979).

- Tres componentes de índole afectiva, económica, y moral (Allen y Meyer, 1990). 
- Cinco dimensiones en las que se distinguen aspectos de la ética del trabajo, la implicación con el propio grupo y cometido, y el compromiso con el todo organizativo y la propia carrera (Randall y Cote, 1991).

Ha generado una gran confusión, lo que justifica el desarrollo de un nuevo marco filosófico que permita aclarar qué es este tipo de compromiso, cómo se desarrolla, y en base al cual se proponga un modelo de estudio que guíe el marco empírico de las investigaciones futuras.

El objetivo de este trabajo se concreta en la discusión y propuesta de un modelo de estudio del Compromiso Organizacional con una triple intención:

a) Establecer un marco filosófico para el concepto mismo de Compromiso Organizacional desde una doble perspectiva: la del trabajador; y la de la organización en base al estilo de dirección que evoca un mayor nivel de compromiso de los empleados. Los especialistas en análisis factorial, con frecuencia se han centrado en atribuir un significado físico a las ponderaciones que determina la matriz de componentes principales, olvidándose de que las interpretaciones de este tipo no pueden basarse solo en las matemáticas, puesto que es imprescindible contar con conocimientos relativos a la naturaleza de la medida (Jay, 2004).

b) Discutir la propuesta tridimensional de Allen y Meyer (1990) debido a que es la más generalmente aceptada por la comunidad científica; ya que no todas las dimensiones de su constructo miden Compromiso Organizacional. De acuerdo con el soporte filosófico del apartado anterior, se discute la naturaleza de cada una de sus dimensiones para concluir si son fuente de este tipo de compromiso, o de otro cualquiera que resulte ajeno a los intereses de la empresa.

c) En base a los dos apartados anteriores y a los análisis factoriales de la investigación que se ha realizado con carácter previo (Ávila, 2019), definir y concretar la propuesta misma del modelo y realizar algunas recomendaciones sobre la elaboración de futuras escalas de medida del Compromiso Organizacional.

Para ello, el presente trabajo, además de esta introducción se articula en cinco partes:

Primera, que presenta una síntesis de aspectos ya tratados por la literatura científica sobre este tipo de compromiso (qué es el Compromiso Organizacional, cuál es su definición, y cuáles son sus principales modelos de estudio); segunda, que fija el marco filosófico del Compromiso Organizacional y trata aspectos relacionados con:

- El empleado. Su motivación; el conocimiento en cuanto a moderador de su conducta; los tipos de bienes que persigue según la ética aristotélica y las necesidades que satisfacen.

- La organización. Tipos de liderazgo y su influencia en el rendimiento y sentido de pertenencia de los empleados.

Tercera, que relaciona los aspectos ya tratados con el modelo tridimensional de Meyer y Allen; cuarta, en la que se define y desarrolla la propuesta de un nuevo modelo de estudio del Compromiso Organizacional con importantes implicaciones para directivos e investigadores; y por último, la quinta, en la que se presentan las conclusiones.

\section{CONCEPTO DE COMPROMISO ORGANIZACIONAL}

A pesar de que el Compromiso Organizacional es un constructo ampliamente estudiado, en la actualidad sigue generando una gran cantidad de conocimiento. En sus primeras aproximaciones se definió como: 
-El nivel en que participa activamente un individuo cuando persigue sus propias metas (Allport, 1943).

-“El compromiso se presenta cuando una persona, por inversiones pretéritas, vincula intereses ajenos con una consistente línea propia de actuación” (Becker, 1960, p. 32).

-La actitud que une a una persona con su organización (Sheldon, 1971).

-Vínculo o atadura psicológica (Porter et al., 1974).

-"La fuerza relativa de identificación e implicación de un individuo con una determinada organización” (Mowday et al., 1982, p. 27).

Más tarde, Meyer y Herscovitch (2001, p. 301) exponen la idea de la existencia de un hilo conductor en todas las definiciones habidas hasta ese momento.

“Compromiso es una fuerza que une a una persona con el curso de una acción relevante a uno o más objetivos. Como tal, se distingue de otras formas de motivación basadas en el intercambio, así como de actitudes dirigidas a objetivos, y pudiendo influir en el comportamiento incluso en la ausencia de motivación extrínseca o de actitudes positivas.”

Para apuntar, a continuación, que el compromiso se constituye como "un marco mental o estado psicológico que impulsa a un individuo hacia el curso de la acción” (Meyer y Herscovitch, 2001, p. 303). Apreciaciones que en un intento de definición posterior quedaron delimitadas como:

"El vínculo de un individuo a una organización y, por lo tanto, una reducción de la probabilidad de abandono. Por ello, consideramos el compromiso como un sentimiento del individuo hacia la organización que le condiciona hacia un particular comportamiento o línea de actuación que disminuye la probabilidad de abandono de la organización.” (Juaneda y González, 2007, pp. 3602-3603).

Perspectivas todas, que lo presentan finalmente como una forma de adhesión del trabajador con las metas y valores de la organización, que deriva en un fuerte deseo de continuidad incluso en entornos individualistas, como pudiera ser, entre otros casos, el de los desarrolladores de software, o el del personal empleado en labores de teletrabajo (Scholarios y Marks, 2004). A continuación, vamos a exponer en primer lugar los principales enfoques y modelos de este tipo de compromiso (apartado 2.1), para posteriormente hacer lo propio con el modelo de Allen y Meyer (apartado 2.2)

\subsection{Principales enfoques y modelos de estudio de este tipo de compromiso}

A finales del siglo pasado los enfoques que predominan en el estudio del Compromiso Organizacional son tres:

-El compromiso de cálculo o intencionado (Becker, 1960). Perspectiva que entiende que el trabajador continúa o no en la organización en base al coste de oportunidad que le pudiera suponer su abandono. La voluntad del empleado por permanecer en la empresa queda supeditada a su sola conveniencia.

-El compromiso actitudinal. Definido como la ligazón psicológica que une al trabajador con la empresa, que le impulsa hacia un desempeño superior al que tiene por obligación. Su principal referente de estudio es el equipo de Porter, que en base a sus trabajos iniciales, centrados en averiguar el impacto que tiene la satisfacción laboral y el Compromiso Organizacional en la rotación de los empleados (Porter et al., 1974), desarrollaron un modelo de medida del compromiso que utiliza el cuestionario conocido como OCQ de Porter (Organizational Commitment Questionnaire) (Mowday et al., 1979). Según sus autores, pretendían una herramienta de aplicación 
fácil y genérica (Porter et al., 2005), que se sigue empleando con frecuencia (Bermejo et al., 2014; González et al., 2014; Serra et al., 2014).

-El modelo tridimensional de Meyer y Allen. En el año 1984 proponen un modelo de dos dimensiones: afectiva en base al enfoque actitudinal, y de continuidad en relación al compromiso de cálculo (Meyer y Allen, 1984), que completan más tarde con la incorporación de la dimensión normativa, basada esta en la obligación moral que siente el trabajador por contribuir a los objetivos de la empresa (Allen y Meyer, 1990).

Enfoques, que se acabarán traduciendo en una propuesta más que generalizada de modelos multidimensionales tales como: el que subdivide la dimensión de continuidad de Meyer y Allen en dos, formada una por "el coste de oportunidad ya comentado", y otra "por la falta de alternativas", con lo que pasaría a tener cuatro dimensiones (De Frutos et al., 1998); el constituido por las dimensiones: de continuidad, afectiva, y el compromiso con la propia carrera (Carmeli y Freund, 2004); o el que refleja, los afectos, miedos, y obligaciones, de Juaneda y González (2007), entre otros.

No obstante, los sistemas de control burocrático de antaño, que primaban la antigüedad y la experiencia, han mutado hacia relaciones basadas en el desempeño. Los empleados con mejores habilidades, información superior, y un alto poder negociador, disfrutan de expectativas de trabajo mayores a las que se pudieran dar en la cultura anterior, provocando una orientación laboral cada vez más individualista, que en el campo del comportamiento organizacional ha derivado hacia el estudio del compromiso con el particular desempeño, la propia carrera, o el singular talento (Basak y Vandenberghe, 2016; Cappelli, 2000).

De todos los enfoques y modelos propuestos, el de Meyer y Allen, además de ser el que más base investigadora ha propiciado (Kam et al., 2016; Neves et al., 2018), también cuenta con una aceptación más que generalizada de la comunidad investigadora (Baez-Santana et al., 2019; Bergman, 2006; Meyer y Morin, 2016); aunque quizás, y por eso se discute su propuesta, los investigadores se han dejado llevar en exceso por el seguimiento de un modelo en el que prima la interpretación matemática de los análisis factoriales realizados, en detrimento de la que debiera haberse hecho en base al conocimiento de lo que es y significa el Compromiso Organizacional.

\subsection{El modelo de Allen y Meyer}

Allen y Meyer (1990), con el objetivo de diseñar su escala tridimensional, redactaron 51 ítems de una forma lógica en atención a medir lo afectivo, la continuidad, y lo normativo, según las conceptualizaciones de la figura 1 (algunos eran versiones modificadas de ítems de otras escalas y otros elaborados por ellos mismos), y les añadieron los 15 del OCQ de Porter (Mowday et al., 1979, p. 228); quedando constituido el cuestionario inicial por 66 ítems, que se medían con una escala Likert de 7 puntos, en la que 1 significa "en total desacuerdo", y 7, en "total acuerdo". Con excepción de los ítems del OCQ, que se presentaban en primer lugar, el resto se mostró de forma aleatoria. 


\section{FIGURA 1: MODELO DE COMPROMISO ORGANIZATIVO DE MEYER Y} ALLEN

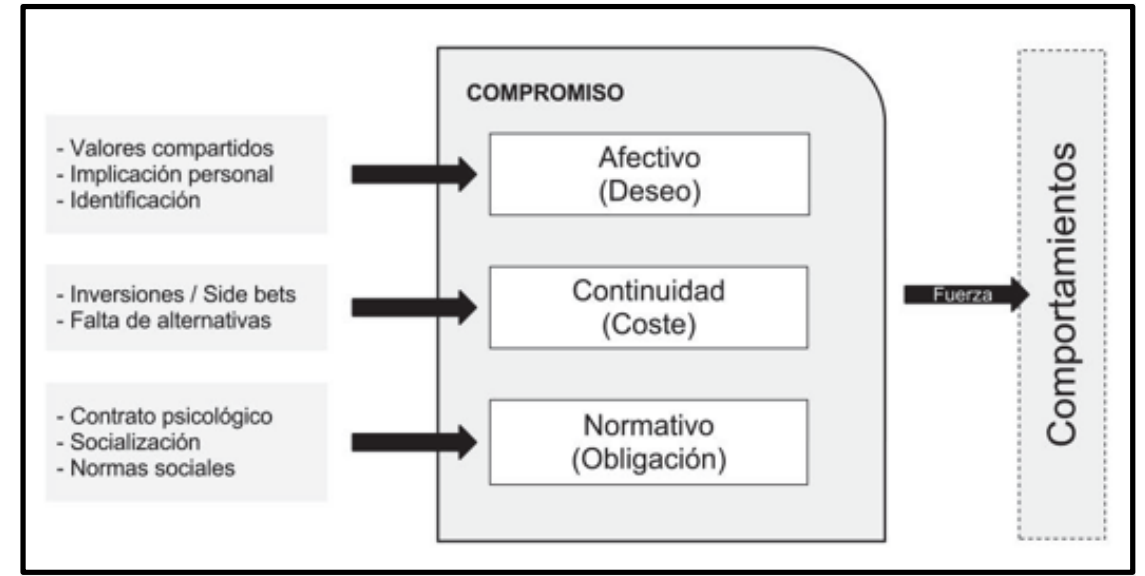

Fuente : (Simo et al., 2013, p. 60).

Se distribuyeron 500 cuestionarios entre los empleados a tiempo completo de dos empresas manufactureras y una universidad, de los que 256 fueron cumplimentados y devueltos correctamente. Posteriormente, y en base a los datos recabados, se realizó una selección de ítems de acuerdo con unos criterios de exclusión (se eliminaban aquellos que presentaban una correlación ítem-total de la escala original, menor que la que se daba con alguna de las otras dos escalas; también, si la información recabada por el ítem era redundante con la de otros; y si su porcentaje de aprobación era superior al 0,75), y se igualó el número de ítems de las tres escalas al de aquella que lo tuviera menor una vez aplicados los criterios excluyentes. Esto es, si la escala afectiva hubiera quedado formada por 9 ítems, y la normativa y la de continuidad por 10, se hubiera optado porque todas ellas tuvieran 9.

A continuación, tras realizar un análisis factorial en el que se empleó como método de extracción de factores el de componentes principales, y de rotación, el ortogonal tipo varimax, se extrajeron tres factores de 8 ítems cada uno (Anexo 1), que daban una explicación de la varianza del 58,8 por cien en la dimensión afectiva (alfa de Cronbach 0,87); 25,8 por cien en la de continuidad (alfa de Cronbach 0,75); y 15,4 por cien en la normativa (alfa de Cronbach 0,79) (Allen y Meyer, 1990, p. 6). En todos los casos, los ítems ofrecían su mayor saturación en el factor en el que ya se habían conceptualizado previamente; esto es, si el ítem fue concebido en su versión lógica como parte de la escala afectiva, su mayor saturación se daba también en ella. Finalmente, su propuesta se concretó en base a las siguientes tres dimensiones:

- Afectiva. Ligazón emocional que une al trabajador con la organización (Kanter, 1968), consecuencia de su apego con los objetivos y valores de su empresa al margen de un interés puramente instrumental (Buchanan, 1974), que se traduce en un fuerte deseo de conseguir el logro organizativo (Mowday et al., 1979). De las tres dimensiones de su modelo, la afectiva es la que presenta mayor cantidad de estudios (Cernas y Nava, 2019; Meyer y Allen, 1997; Meyer et al., 2002; Poon, 2013), lo que demuestra el sentir general de la comunidad investigadora sobre cuál es la principal fuente de Compromiso Organizacional.

Los comportamientos laborales más deseados, tales como el alto desempeño, la puntualidad, la conducta que va más allá de lo que la sola descripción del puesto determina, junto con una actitud que procura lo mejor para la empresa, se correlacionan más con un alto nivel de este tipo de compromiso (Arciniega, 2002). Lo afectivo, se muestra relacionado con 
los sentimientos y las emociones del individuo, con su capacidad de ser más hábil y de adquirir control sobre la realidad que le circunda (Pérez López, 1985b).

Más recientemente, se ha apuntado la idea de que una investigación tan fragmentada como la actual, lejos de resultar clarificadora, ha complicado la situación; de ahí que se proponga "un marco conceptual en el cual el compromiso afectivo o el apego emocional con la organización, sea el núcleo esencial del Compromiso Organizacional” (Mercurio, 2015, p. 389).

- De continuidad. Coste de oportunidad que pondera un trabajador cuando sopesa cambiar de organización y hace balance de las ventajas e inconvenientes de permanecer en ella, o de incorporarse a otra (Kanter, 1968); implica un sentimiento de apego psicológico de carácter instrumental independiente del afecto (Farrell y Rusbult, 1981).

- Normativa. Obligación moral que siente el trabajador por conseguir los objetivos de su empresa; al estar fundamentada en un juicio moral, y por tanto racional, se presenta como una ligazón psicológica distinta de la afectiva (Bergman, 2006). Moralidad que a entender de González-Cruz y Guillén (2008, p. 404), sería de escasa condición si solo fuera el resultado de una norma social.

"No hay referencia explícita a un juicio moral interno y comportamiento derivado. Esto refleja una importante distinción entre las dos dimensiones, pero da una concepción muy pobre de una moralidad que solo queda supeditada a un conjunto de normas sociales comúnmente aceptadas."

En la actualidad y tal como se ha dicho, el modelo de Meyer y Allen es el más comúnmente aceptado; no obstante, y a pesar de que los análisis factoriales informan de la multidimensionalidad del constructo, no resulta del todo claro que se concreten convergentes en sus consecuencias, ni que todas sus dimensiones puedan ser calificadas como tal, de ahí que su modelo, y los similares que como combinación de investigaciones anteriores han surgido también, hayan sido desafiados y puestos en entredicho (Bergman, 2006; Stazyk, et al., 2011).

La alta correlación de las dimensiones afectiva y normativa $(0,77)$ (Meyer et al., 2002, p. 28), que invita a pensar en una sola de ellas (Cohen, 2003; Jong-Wook et al., 1997), y la apreciación de que la dimensión de continuidad solo atiende a los propios intereses y a la rotación, por lo que más que un componente de Compromiso Organizacional se trataría de un marco específico de un comportamiento determinado, ponen al modelo en duda, ya que si la continuidad correlaciona solo con la rotación del trabajador, se debieran proponer otros modelos similares, que se mostraran predictivos de comportamientos específicos tales como el absentismo, el desempeño,...(Solinger et al., 2008).

\section{MARCO FILOSÓFICO}

Entender que el estilo de liderazgo que percibe el trabajador junto con sus tipos de motivación, conocimiento, bienes y necesidades que satisfacen, tienen tres dimensiones, es útil y necesario para comprender la complejidad y relación que se da entre los conceptos citados y el Compromiso Organizacional, y por ende, para establecer un marco filosófico que permita una mejor definición y comprensión de este tipo de compromiso. A continuación, se tratan dichos aspectos desde dos perspectivas complementarias la una de la otra: la del trabajador, y la de la organización. 


\section{1 Perspectiva del trabajador. Motivación, conocimiento, tipos de bienes y necesidades}

Según el modelo antropológico o humanista, la motivación de una persona puede venir dada por la búsqueda de consecuencias de naturaleza extrínseca, intrínseca, y trascendente (García Parra, 2004; Pérez López, 1985b; Ruiz de Alba, 2013), concretadas en la obtención de bienes útiles, placenteros, y morales (Aristóteles, 2011) (tabla 1).

\begin{tabular}{|c|c|c|c|c|}
\hline \multicolumn{5}{|c|}{$\begin{array}{l}\text { TABLA-1: TIPOS DE MOTIVACIÓN, BIENES QUE LAS SATISFACEN Y } \\
\text { SENTIMIENTOS QUE EVOCAN }\end{array}$} \\
\hline $\begin{array}{l}\text { Tipos de } \\
\text { motivación }\end{array}$ & $\begin{array}{l}\text { Dimensiones del } \\
\text { Conocimiento }\end{array}$ & $\begin{array}{l}\text { Bienes que las } \\
\text { satisfacen }\end{array}$ & $\begin{array}{l}\text { Necesidades que } \\
\text { cubren }\end{array}$ & $\begin{array}{l}\text { Sentimientos que } \\
\text { evocan }\end{array}$ \\
\hline Extrínseca & Operativa & Útiles & Materiales & Placer \\
\hline Intrínseca & Afectiva & Placenteros & De Conocimiento & Disfrute en el hacer \\
\hline Trascendente & Especulativa & Morales & Afectivas & Plenitud \\
\hline
\end{tabular}

Tabla en la que se pueden apreciar las siguientes relaciones:

-Extrínseca. El individuo transacciona con el entorno a través de su comportamiento para conseguir de otras personas bienes útiles (incentivos, retribución, felicitaciones... que percibe por su trabajo), que cubren sus necesidades materiales y le procuran placer en el momento de su logro. La acción es ejecutada por una persona que recibe de otra el incentivo atribuido a la misma.

-Intrínseca. La persona realiza una acción con el deseo de obtener bienes placenteros que se derivan de su ejecución misma (realizar un trabajo, actividad, o cometido, que le resulta gratificante), lo que satisface sus necesidades de conocimiento y le evoca sensaciones de poder, dominio y seguridad, con disfrute en el hacer. La acción y su recompensa tienen origen y final en la misma persona.

-Trascendente. La persona ejecuta una acción buscando los efectos que esta tiene en otros individuos para la obtención de bienes morales (ayudar desinteresadamente a un compañero de trabajo de reciente incorporación), que cubren sus necesidades afectivas de darse a los demás y recibir de ellos, lo que podría evocar sensaciones de plenitud. La acción es ejecutada por una persona con el deseo de beneficiar a otra en sus consecuencias.

Sin embargo, el impulso que siente una persona en un momento concreto por satisfacer una necesidad, no solo viene determinado por su motivación, también necesita de su conocimiento (no se puede estar motivado por lo que se desconoce que existe), que también presenta tres dimensiones (Gómez-Llera, 1990; Pérez López, 1985b):

-Especulativa. Que permite a la persona anticipar el resultado de su acción (saber, con mayor o menor grado de certeza, que si un atleta se entrena estará en mejor disposición de competir es algo que atañe al conocimiento especulativo).

-Afectiva. Que adelanta la forma en que la persona se verá afectada por el resultado de su acción (saber cómo se sentirá después de cada entrenamiento y prueba compete a lo afectivo) 
-Operativa. Que viene determinada por la capacidad que tiene una persona para ejecutar una acción sabiendo qué tiene que hacer para llevarla a cabo (saber qué hacer y cómo emplearse en el transcurso de los entrenamientos corresponde al conocimiento operativo).

Así, una persona puede saber cómo actuar (operativo) para conseguir un resultado que le atrae (afectivo) pero decide no hacerlo porque considera que sería poco adecuado o injusto (especulativo). El conocimiento especulativo, enmarca y sitúa a los otros dos en relación a lo que es adecuado (análisis coste-beneficio) o correcto (análisis sobre las bondades éticas de la acción). Al presentar de forma secuencial los conceptos aquí tratados, se podría inducir a pensar que es así como se producen los hechos; pero tal como apuntan Robbins y Judge (2009, p. 75), la cognición y el afecto muchas veces se presentan entrelazados:

"En particular, la cognición y el afecto son inseparables de muchos modos. Por ejemplo, imagine que concluyó que alguien lo acaba de tratar de forma injusta. ¿No es probable que albergue sentimientos al respecto, que ocurren virtualmente de manera instantánea con el pensamiento? Así, la cognición y el afecto están entrecruzados.”

Resulta habitual que el desempeño de cualquier trabajador venga soportado por estos tres tipos de motivos según sus circunstancias y personalidad, esto es, que persiga obtener un salario (extrínseco), desarrollar y disfrutar de su cometido (intrínseco), y ayudar a sus compañeros y compañía a obtener mejores resultados (trascendente). La "calidad humana” de un trabajador estará basada en su "calidad motivacional”; así, a un empleado le moverá fundamentalmente lo extrínseco, y a otro, lo intrínseco o trascendente. Es por ello que quien solo busca bienes materiales con la intención de conseguir placer, recibirá el calificativo de poco humano y egoísta; y quien se emplea habitualmente dándose a los demás, de generoso y humano (Pérez López, 1985b).

3. 2 Perspectiva de la organización. Tipos de liderazgo, y su influencia en el rendimiento y estabilidad de los empleados

Desde un punto de vista organizacional, el estilo de liderazgo se concreta como un antecedente del compromiso y, por ende, del rendimiento y estabilidad laboral de los empleados desde el punto de vista de la rotación externa y voluntaria (Chiavenato, 2009) (tabla 2).

\section{TABLA 2: TIPO DE LIDERAZGO, RENDIMIENTO, ESTABILIDAD, Y VÍNCULO DE PERTENENCIA}

\begin{tabular}{lllll}
\hline $\begin{array}{l}\text { Tipo de } \\
\text { Liderazgo }\end{array}$ & $\begin{array}{l}\text { Vínculo de } \\
\text { pertenencia }\end{array}$ & Rendimiento & Comportamiento & Estabilidad \\
\hline Transaccional & $\begin{array}{l}\text { Extrínseco/Contractual } \\
\text { Propio Interés }\end{array}$ & In-role behavior & uniformidad & Menor \\
Transformador & $\begin{array}{l}\text { Técnico/Profesional } \\
\text { Adhesión }\end{array}$ & $\begin{array}{l}\text { Extra-role } \\
\text { behavior }\end{array}$ & alineación & \\
Trascendente & $\begin{array}{l}\text { Lealtad/Identificación } \\
\text { Compromiso Personal }\end{array}$ & $\begin{array}{l}\text { High value-added } \\
\text { partnership }\end{array}$ & unidad & Mayor \\
\hline Fuente: Elaboración propia a partir de (Cardona, 2000; Chinchilla, 2000; Pérez López, 1985a). \\
\hline
\end{tabular}


En consonancia con el modelo humanista de la motivación, el antropológico de liderazgo propone la existencia de tres estilos de dirección (Cardona, 2000; Pérez López, 1985a):

-Transaccional. La dirección se emplea en base a la sola transacción, en el convencimiento de que las personas solo se mueven por incentivos que pueden obtener de su entorno. La única fuente de motivación que reconoce en el empleado es la extrínseca; así, para garantizarse su mejor control y eficacia, solo maneja los procesos y el sistema de incentivos, ya que la dirección solo está interesada en la eficacia de los empleados. El liderazgo transaccional busca el propio interés e induce a comportamientos uniformes de mínimos (in-role behavior), ya que el empleado solo hace lo imprescindible para no quedar señalado.

-Transformador. La dirección reconoce que el trabajador además de moverse por motivos externos también lo hace por motivos internos. Desde este punto de vista, la organización no solo debe atender a un criterio mínimo de eficacia como en el modelo transaccional, sino que además debe buscar un mínimo de atractividad para que la motivación interna del empleado se exprese. El liderazgo transformador busca la adhesión técnico profesional y la alineación de voluntades, evocando comportamientos extra-role que van más allá de lo que se tiene por obligación.

-Trascendente. La dirección busca añadir a los criterios de eficacia y atractividad del modelo anterior, basados en la motivación extrínseca e intrínseca del empleado, el para qué de la motivación trascendente. El liderazgo trascendente fomenta el compromiso y la unidad de los empleados y su mayor rendimiento (high value-added partnership)

En atención al estilo de liderazgo, los colaboradores que solo son evocados por lo extrínseco, se muestran menos leales y productivos (la más baja lealtad) que los que además se pueden expresar intrínsecamente (lealtad media); presentando, estos últimos, menos lealtad y productividad que los que tratan de contribuir y, por tanto, trascender hacia su organización (máxima lealtad) (Cardona, 2000; Chinchilla, 2000), puesto que mantener relaciones de calidad con los jefes respectivos, propicia unos mayores niveles de rendimiento, de satisfacción en el trabajo, y de compromiso (Hansen et al., 2014). Según Bass (1999, p. 23):

"Al involucrar a los propios seguidores y despertar en ellos sus motivaciones inconscientes, los líderes transformadores suscitan selectivamente el sentimiento de logro inconsciente de los seguidores, de afiliación, de motivación de poder (y otras motivaciones). Motivaciones que, siendo inconscientemente estables, tienen fuertes y duraderas consecuencias comportamentales...En última instancia esto incrementa el compromiso con la misión ya que resulta de un mayor auto compromiso.”

\section{DISCUSIÓN}

Tal como ha quedado dicho, una investigación tan fragmentada como la actual, y una crítica cada vez más sostenida del modelo de Meyer y Allen, nos sitúan ante la necesidad de definir y desarrollar una nueva propuesta de estudio del Compromiso Organizacional, lo que implica, con carácter previo, discutir la bondad de su modelo tridimensional (dimensión afectiva, de continuidad, y normativa) en base al marco filosófico expuesto, y analizar, si todas las dimensiones del constructo se pueden considerar componentes de este tipo de compromiso, para concretar, a continuación, la nueva propuesta. 


\subsection{Dimensión afectiva}

Cada vez hay más estudios que presentan a la componente afectiva como al principal elemento evocador de Compromiso Organizacional: "el concepto de compromiso afectivo parece ser más útil a la hora de predecir el comportamiento de ciudadanía organizacional dirigido hacia la organización y la intención de continuar en el futuro” (M. Dávila y Jiménez, 2012, p. 244); tal es así, que según Jaros (2007) se plantearía el dilema de si “el componente afectivo es una de las tres dimensiones del compromiso, o lo afectivo es un componente tan fuerte que es realmente distinto de los componentes normativo y de continuidad, y subsumido en una orientación general hacia su trabajo” (p.17), por lo que a entender de Mercurio (2015), se debiera concretar como el núcleo fundamental de este tipo de compromiso, y así enfocar su estudio y aplicación práctica futura (Cernas y Nava, 2019).

\subsubsection{La dimensión afectiva y su marco filosófico de referencia}

-En el trabajador, la componente afectiva se corresponde con su motivación intrínseca, la que persigue bienes placenteros que le evocan disfrute en el hacer (trabajar en marketing cuando ese es el gusto del empleado) como consecuencia de un mejor control y dominio de su actividad. Bienes de los que capta su valor por la vía del conocimiento afectivo, en el atractivo que le procura el cometido mismo (tabla 1). Así, el empleado establece una ligazón afectiva con su organización, que está basada en realizar un trabajo que le gusta y desafía, y que se encuentra al alcance de sus talentos, lo que le permite entrar en un proceso de mejora personal contínuo (Csikszentmihalyi, 2007).

-En lo organizacional, el liderazgo que se muestra transformador evoca comportamientos de lealtad en los empleados, y procura la alineación técnico profesional de sus intereses con los de la empresa, de lo que se deriva un alto nivel de compromiso afectivo y rendimiento extra-rol (tabla 2). Para que la actividad de recursos humanos impacte de forma positiva en el Compromiso Organizacional, se debe centrar en el compromiso afectivo de los trabajadores (Kehoe y Wright, 2010), puesto que aspectos como el compromiso o la motivación de los empleados, no son en sí mismos políticas de recursos humanos, sino que se encuentran en las consecuencias que se derivan de las prácticas implantadas por la empresa (Maella, 2010).

Los ítems de la escala afectiva de Meyer y Allen tales como:

-Yo estaría muy feliz de pasar el resto de mi carrera en esta organización.

-Disfruto discutiendo de mi organización con gente ajena a ella.

-Realmente percibo los problemas de la organización como si fuesen míos.

-Esta organización tiene un significado personal muy grande para mí.

-Yo no percibo un fuerte sentido de pertenencia con mi organización ...

Hacen referencia a una ligazón afectiva del trabajador con la organización de carácter reactivo, que tratan de averiguar lo evocado por ella en él, pero no de su interés por conseguir lo mejor para la empresa, ya que el empleado comprometido busca alcanzar las metas de su organización de forma satisfactoria mostrando todo lo positivo que hay en ella (Claure y Böhrt, 2015); de ahí que se debieran definir otro tipo de ítems que informen sobre la disposición que tiene el empleado para alcanzar el logro organizativo. No basta con conocer los sentimientos evocados por la empresa en el trabajador, puesto que lo relevante, desde el punto de vista del Compromiso Organizacional, es conocer su empeño por cumplir los objetivos de la misma. 
Como consecuencia de lo apuntado, cabe deducir que un empleado se sentirá ligado afectivamente con una empresa y proyecto concretos, cuando le procuren un entorno y cometidos que le satisfagan. La ligazón afectiva se establece con una realidad determinada en la que los intereses del trabajador y de la organización están alineados; de ahí que un individuo se pueda mostrar comprometido con una empresa y falto de compromiso con otra, por lo que se puede afirmar que los conceptos de compromiso afectivo y organizacional se confunden en uno solo. El compromiso afectivo es Compromiso Organizacional.

\subsection{Dimensión de continuidad}

A entender de algunos autores, el compromiso de continuidad daría explicación a la causa por la que un empleado permanece en una organización pero no a su interés de conseguir lo mejor para ella, puesto que carecer de alternativas laborales ajenas a su actual empresa, o teniéndolas que no le resulten atractivas a tenor del miedo a perder determinadas prestaciones o reconocimiento, no implica que tenga voluntad de logro en lo colectivo (Ashman y Winstanley, 2006; Jong-Wook et al., 1997); tal como refiere Swailes (2002, p. 169), "resulta difícil imaginar a los directivos, considerar que sus empleados están comprometidos porque encuentran difícil dejar la organización”.

En un metaanálisis basado en 92 estudios diferentes, se encontró un coeficiente de correlación entre el componente de continuidad y el afectivo de 0,05 (Meyer et al., 2002, p. 28), siendo las correlaciones entre el desempeño laboral y el compromiso de continuidad de 0,07; y de 0,16 con el afectivo (correlaciones prácticamente nulas) (Meyer et al., 2002, p. 36); por lo que según Solinger et al., (2008), parece más que dudosa la existencia de convergencia entre la componente afectiva y la de continuidad; esto es, si la componente afectiva mide Compromiso Organizacional, la de continuidad lo hará con otro tipo de actitud o disposición que nada tiene que ver con ella.

\subsubsection{La dimensión de continuidad y su marco filosófico de referencia}

-En el trabajador, el compromiso de continuidad se corresponde con su motivación extrínseca, la que persigue satisfacer una necesidad de tipo material concretada en un bien útil (conseguir una mejor situación laboral), que le producirá placer. Permanecer en la organización no le resulta atractivo sino interesado ya que los objetivos de su actual empresa no existen en sus cavilaciones (tabla 1). Dentro de los componentes propuestos por Meyer y Allen, el de continuidad lo es en atención a la sola transacción; el trabajador valora la mejor de las opciones disponibles y en atención a lo puramente extrínseco, decide si permanece o no en la organización. Cuando Meyer y Herscovitch tratan la definición de compromiso en su meta estudio (2001), se refieren a la fuerza que une a una persona con el curso de una acción que se encamina hacia objetivos de la organización que tiene como propios, añadiendo: "pudiendo influir en el comportamiento incluso en la ausencia de motivación extrínseca o de actitudes positivas” (Meyer y Herscovitch, 2001, p. 301), por lo que cabría preguntarse: ¿dónde se encuentra ese compromiso cuando el trabajador solo sopesa continuar en la organización en función de lo que solo le interesa a él?

-En lo organizacional, se relaciona con el liderazgo transaccional, que evoca comportamientos uniformes faltos de iniciativa y de pensamiento en el grupo, y rendimientos y lealtades de mínimos (Cardona, 2000), que son consecuencia de su bajo nivel de compromiso (solo se busca el propio interés) (tabla 2). Ante este tipo de liderazgo, el trabajador se emplea de una forma muy medida (in-role behavior) 
para no quedar señalado por la dirección, y desea cambiar de organización (menor estabilidad).

Los ítems de la escala normativa de Allen y Meyer (1990) tales como:

-Ahora, aunque quisiera, sería muy difícil para mí dejar la organización.

-Si decidiera dejar la organización, mi vida quedaría demasiado desestructurada.

-Ahora no sería demasiado costoso para mí dejar mi organización.

-Actualmente, quedarse en la organización es más una necesidad que un deseo.

-Una de las principales razones por las que continúo trabajando para esta organización sería que dejarla requeriría un considerable sacrificio personal, en otra organización no podría igualar mis actuales beneficios generales...

Solo preguntan por el deseo del trabajador de continuar en la empresa en función de su sola conveniencia, pero no lo hacen por su interés en procurar un mejor desarrollo organizacional, por lo que se hace dificil pensar que esta dimensión sea una componente del Compromiso Organizacional. Meyer y Allen definen la dimensión de continuidad sobre la base de que permanecer en la empresa sin más es una forma de compromiso, y sobre dicha suposición, redactan los ítems de la escala; posteriormente, y como consecuencia de los análisis factoriales, hay ocho de ellos que saturan en la misma dimensión de la que formaban parte en su concepción lógica, concluyendo que al resultar así, se trata de un factor de compromiso (profecía autocumplida), con lo que se entra de lleno en lo que Jay llama cosificación: "Los especialistas en el análisis factorial han incurrido a menudo en la tentación de la cosificación, o sea atribuir un significado físico a todos los componentes principales muy marcados" (Jay, 2004, p. 252).

A la máxima estadística de que todo lo que existe puede ser medido, los especialistas en análisis factorial han añadido el postulado contrario: si se puede medir es que existe; postulado simétrico del anterior que puede resultar falso (Tuddenham, 1962). Tal como ya ha quedado dicho, establecer que existe un factor de ocho ítems que se corresponde con el inicialmente definido como compromiso de continuidad, no implica que sea Compromiso Organizacional, puesto que dicha dimensión no mide la intención del trabajador por conseguir lo mejor para la empresa, sino su solo deseo por continuar en ella en atención a sus únicos intereses.

El "compromiso de continuidad" no puede ser calificado como Compromiso Organizacional, ya que lo único que mueve al trabajador es la defensa de su propio interés; Meyer y Allen cayeron en la tentación de aceptar que hay una "cosa” detrás de dicha dimensión, a la que denominaron compromiso de continuidad, porque estaban desarrollando un modelo de estudio del Compromiso Organizacional, y forzaron su denominación para que se tuviera como una componente más de su constructo. En definitiva, no se puede aceptar que un trabajador está comprometido con su organización cuando en lo único que piensa es en su propio beneficio. $E l$ compromiso de continuidad no es Compromiso Organizacional, es un compromiso del trabajador con sus propios intereses

\subsection{Dimensión normativa}

La componente normativa del compromiso, inicialmente concebida como un derecho moral que se arroga el empleado para continuar en la organización al margen de que obre en su mejora, o como la satisfacción evocada por ella en él con el paso del tiempo (Marsh y Mannari, 1977), pasó, más tarde, a ser considerada como una forma de compromiso más proactiva, en la que el trabajador se obliga a actuar de manera que cumpla con sus obligaciones (Wiener, 1982). Posteriormente, Meyer y Allen (1997) se refieren a ella como a un tipo de vínculo que genera lealtad y dedicación, aunque tal como ya ha quedado dicho, no se hace referencia explícita a un 
juicio moral del trabajador, puesto que se remite a la obligación de cumplir con la pura norma social (González-Cruz y Guillén, 2008). A pesar de que los componentes afectivo y normativo muestran patrones de relación similares -tanto en antecedentes como en consecuentes-, a menudo, la magnitud de los mismos es diferente (Meyer et al., 2002); de ahí que "el concepto de componente normativo resulta problemático porque parece que hay una considerable superposición con el afectivo...no está del todo claro cómo se pueden separar conceptualmente el uno del otro” (Jong-Wook et al., 1997, p. 971). Un año más tarde, y según de Frutos, Ruiz, y San Martín (1998, p. 365), ambos componentes se relacionan y constituyen una indiferenciada parte esencial del compromiso:

"Existen indicios de que la parte central del compromiso es atribuible a los vínculos afectivos que establece el individuo con su entorno laboral y a la percepción de una obligación normativa a continuar con la labor que se desempeña dentro de la organización. Ambos aspectos se encuentran relacionados entre sí y se influyen mutuamente en la dirección de su incremento (o disminución)”.

Más tarde, Cohen (2003) se suma a la crítica; si ambas escalas no son diferentes para qué mantenerlas. A mayor abundamiento, "sin demostrar efectos diferenciales en los resultados, la utilidad de retener ambos constructos no está clara” (Bergman, 2006, p. 659).

Más recientemente, se apunta la idea de que las escalas normativa y afectiva entremezclan aspectos volitivos de la naturaleza humana (racionalidad moral y ética) con otros sentimentales (implicación y compromiso emocional), que debieran separarse más ampliamente, y que, en todo caso, requerirían una nueva definición y ampliación del componente normativo (GonzálezCruz y Guillén, 2008).

\subsubsection{La dimensión normativa y su marco filosófico de referencia}

-En el trabajador, la componente normativa se corresponde con la motivación trascendente, que persigue bienes morales que cubren sus necesidades afectivas y le evocan sensación de plenitud (ayudar a un joven directivo en su desarrollo). Bienes de los que capta su valor por vía del conocimiento especulativo, en el que reside su capacidad racional de obligarse a hacer aquello que es correcto hacer (implica tener una conciencia rectamente formada) (tabla 1). En este caso, no se emplea empujado por su afán de realizar actividades que le gustan, como en la dimensión afectiva, sino por su deseo de ayudar a la empresa, compañero o equipo, a obtener mejores resultados. Su finalidad es el “otro”, cuando en la componente afectiva es “él mismo”.

-En lo organizacional, el liderazgo que se muestra transcendente, evoca comportamientos de unidad, de rendimiento máximo (high value-added partnership), y de la más alta lealtad que se corresponden con un alto nivel de compromiso personal (tabla 2). El trabajador que en su condición particular se obliga a ayudar a los demás, encuentra en este estilo de dirección la posibilidad de expresar su compromiso personal, que no organizacional, con determinados principios de carácter ético y moral.

Las preguntas de la escala normativa de Meyer y Allen tales como:

-Creo que la gente cambia de empresa con demasiada frecuencia.

-No creo que una persona deba ser siempre leal a su empresa.

-Saltar de una organización a otra ya no me parece falto de ética.

-Una de las principales razones por las que continúo trabajando para esta organización es que creo que la lealtad es importante y por tanto siento la obligación moral de permanecer en ella... 
Hacen referencia implicita a que la lealtad y la obligación de permanecer, son dos formas sinónimas de compromiso, con lo que se proyecta la idea de que cambiar de organización no es correcto; olvidando que en determinadas ocasiones lo correcto es cambiar de empresa (¿es ético continuar en una sociedad que defrauda y opera de forma ilícita...?).

Cognición y afecto, al estar entremezclados, pueden evocar, al unísono, dos tipos de ligazón: la afectiva de carácter emocional (se emplea con empeño porque le resulta atractivo: componente afectiva), y la racional de carácter ético (se obliga en su cometido porque piensa que es lo que debe hacer en base a sus principios: componente normativa). No obstante, su esencia es diferente, por cuanto en la emocional, el trabajador establece ligazón afectiva con un proyecto y empresa concretos (Compromiso Organizacional), pudiendo no darse con otra organización, en tanto que en la racional, lo hace con un patrón de comportamiento ético de tipo personal (compromiso con la particular creencia de lo que es correcto hacer), de tal forma que el empleado se autocontrola en aquellos aspectos laborales que tiene por correctos, al margen de la organización en la que este se encuentre.

"Las muestras cotidianas de la responsabilidad -puntualidad, precisión, autodisciplina y cumplimiento de sus obligaciones- constituyen el rasgo distintivo de las personas que, en suma, hacen que las cosas sigan funcionando: Se trata, en definitiva, de trabajadores escrupulosos que cumplen las normas, colaboran y se preocupan por las personas con quienes trabajan, ayudando a los recién contratados o poniendo al día a los que regresan después de una ausencia, acuden puntualmente al trabajo, jamás hacen mal uso de las bajas por enfermedad y siempre terminan su trabajo en el tiempo previsto.” (Goleman, 1999, pp. 138-139)

Nuevamente se está en presencia de una profecía autocumplida. Meyer y Allen, definen, con carácter previo, una dimensión de compromiso que denominan normativa, posteriormente los análisis factoriales muestran la existencia de ocho ítems que saturan en esa misma dimensión, concluyendo finalmente que al investigar sobre Compromiso Organizacional, dicha componente debe serlo (de nuevo "la cosificación”); se fuerza el resultado sin entrar a considerar si estamos ante un tipo de Compromiso Organizacional o ante otro distinto de naturaleza personal. No se valora, si la ligazón que se establece es entre el individuo y la empresa, esto es con el todo organizativo (lo propio del Compromiso Organizacional), o entre el individuo y su concepción ética del trabajo como parte de su vida (compromiso con la particular creencia).

Tal como argumentan de Frutos et al. (1998), lo cognitivo y lo afectivo se encuentran relacionados y se influyen mutuamente en su incremento o disminución; un cometido afectivamente atractivo puede languidecer en un entorno falto de ética. El desempeño del trabajador, sobre la base de emplearse en una organización con la cual se siente ligado afectivamente y que le permite realizar un trabajo que le satisface, vendrá condicionado, a mejor, de encontrar un marco ético al que pueda acomodar su conducta, o a peor, en caso contrario; de ahí que, de no encontrar soporte ético adecuado en quien así desea emplearse, pueda disminuir su ligazón afectiva.

El denominado "compromiso normativo" no es Compromiso Organizacional, en realidad se refiere a una dimensión que modera el compromiso afectivo del trabajador. No se puede aceptar que el compromiso que tiene un empleado con la organización, expresado a través de un cometido que le gusta hacer, es idéntico al compromiso que este tiene con determinados principios de carácter personal, que estarán siempre presentes en él al margen de la empresa en la que este trabaje. El compromiso normativo no es Compromiso Organizacional, es un compromiso del trabajador con su propia ética personal. 


\section{PROPUESTA CONCEPTUAL}

Hasta aquí se ha analizado el Compromiso Organizacional a través de enfoques muy diversos, y tal variedad de perspectivas no son otra cosa que el reflejo de lo que en esencia recoge toda definición: el planteamiento mismo del problema, el condicionante que de forma recurrente estará siempre presente en su solución; de ahí, la importancia y necesidad de dar una nueva definición al concepto de Compromiso Organizacional, que se ciña, en función de lo discutido, a su dimensión afectiva dado que se han descartado, por no ser fuente del mismo, los siguientes tipos de compromiso:

-“De continuidad”, ya que el empleado solo se mueve buscando su propio beneficio y no contempla para nada los intereses de su empresa; lo que daría explicación a que dicha dimensión solo correlacione con la rotación de los empleados, y a que el trabajador entregue el mínimo de los esfuerzos requeridos para pasar desapercibido y así evitar sanciones o resultados no deseados (Luchak y Gellatly, 2007). Los rendimientos más pobres se dan cuando la dimensión de continuidad es la prevalente (Kam et al., 2016).

-“Normativo”, porque atiende a patrones de conducta que están presentes en la condición del trabajador al margen de la organización en la que este se encuentre, que hacen referencia a consideraciones éticas y morales de carácter racional. En este caso, la ligazón que expresa el individuo, es con una forma de actuar que tiene por correcta y no con una organización en particular, por lo que la función que cumple lo normativo es la de moderar el comportamiento afectivo del trabajador, reforzándolo, de haber sintonía con los principios y valores de su organización, o entrando en conflicto con ellos y haciéndolo languidecer. Por tanto, nuestra propuesta se concreta en: Definir el Compromiso Organizacional tal como se refleja en el apartado 5.1; y establecer como modelo de estudio del Compromiso Organizacional el compromiso afectivo, tal como se expone en el apartado 5.2.

\subsection{Propuesta primera. Definición de Compromiso Organizacional}

El Compromiso Organizacional es una ligazón afectiva que une al empleado con la organización, que le impulsa a actuar con unos altos niveles de esfuerzo y dedicación en el logro de las metas y objetivos de la empresa; como consecuencia, y derivado de lo afectivo, disminuye su probabilidad de rotación y absentismo, y mejora su desempeño.

\subsection{Propuesta segunda. Modelo de estudio del Compromiso Organizacional}

La esencia del Compromiso Organizacional es el compromiso afectivo (emoción), que en lo organizacional tiene como antecedentes a las políticas de dirección de personas de la organización, y en lo singular del trabajador, viene moderado por su concepción ética (razón) de lo que es correcto hacer; teniendo como consecuentes organizacionales: absentismo, rendimiento, y mejor desempeño (figura 2). Modelo que ha sido desarrollado en base a los trabajos de campo realizados con carácter previo en los que se han empleado técnicas de análisis factorial exploratorio y confirmatorio (Ávila y Pascual, 2019).

En estos trabajos, se utilizó, entre otros cuestionarios, una versión traducida al español del Cuestionario OCQ de Porter (Mowday et al., 1979, p.228), formada por quince items, presentados en una escala de respuestas tipo Likert que va desde totalmente en desacuerdo (1) a totalmente de acuerdo (5); adaptándose, los de expresión negativa, a otros que manteniendo la misma intencionalidad se presentan afirmativos. 
Este fue cumplimentado durante el mes de mayo de 2017 por 706 trabajadores de una empresa multinacional del sector de Seguridad, distribuidos por toda la geografía española y con una edad media de 42 años. La fiabilidad del mismo fue calculada mediante el coeficiente alfa de Cronbach, obteniéndose un valor de 0,95; indicador que se sitúa por encima del mínimo en investigación aplicada $(0,90$ - 0,95) (Nunnally, 1978), lo que permitió confirmar su buena consistencia interna (George y Mallery, 2003). A continuación, se realizaron varios análisis factoriales exploratorios para el estudio de la dimensionalidad del cuestionario, así como un análisis factorial de segundo orden como base de propuesta para un análisis factorial confirmatorio; obteniéndose en todos los casos, que los items del Cuestionario OCQ de Porter, adaptado al español, presentan sus principales saturaciones en un solo factor, que se corresponde con la dimensión afectiva del Compromiso Organizacional.

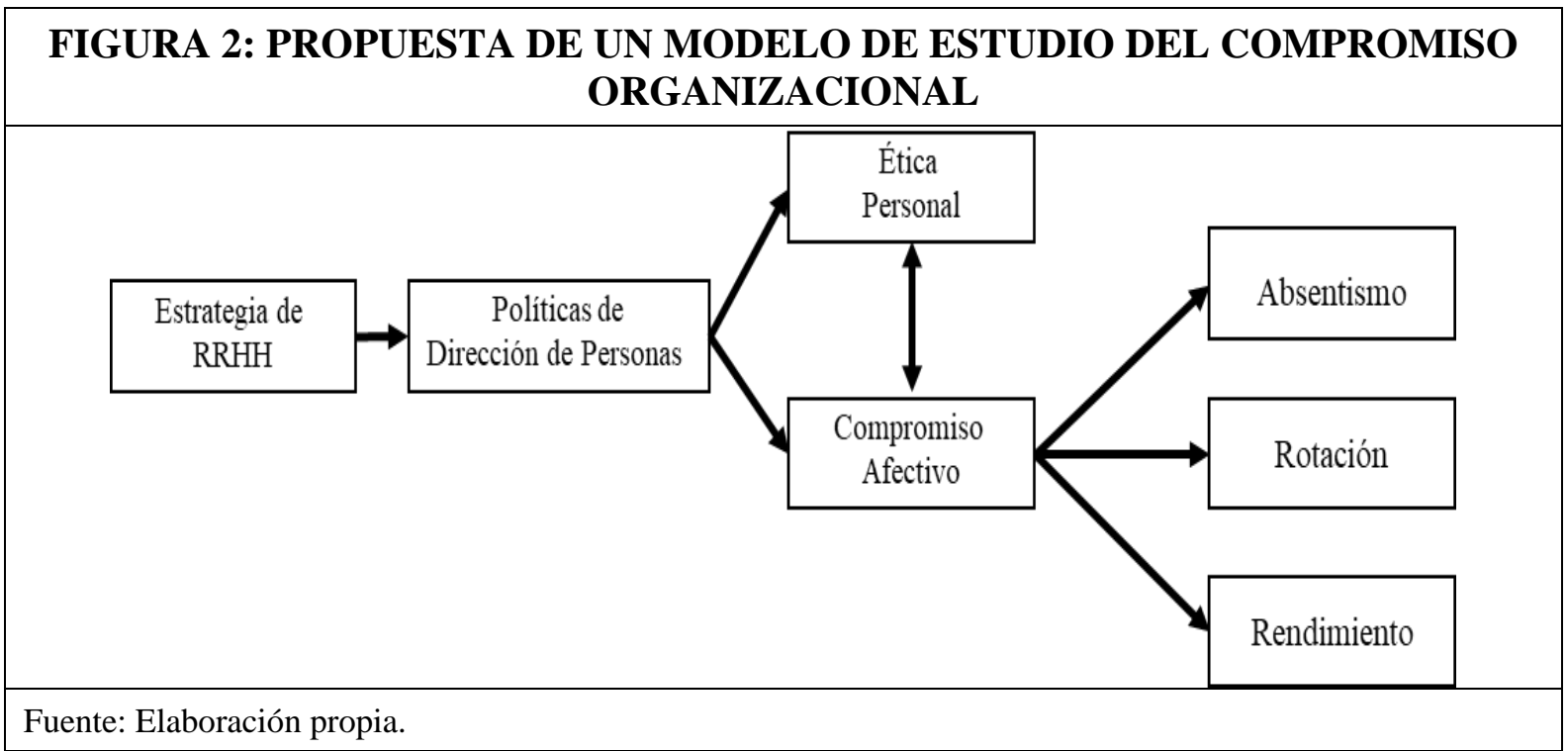

Desde tal perspectiva, a la organización le corresponde facilitar un contexto que favorezca la concreción del compromiso del trabajador, que modera su conducta en función de lo que tiene por correcto hacer. En consecuencia, se establece una relación en que "la persona, aportando su saber-hacer, y por tanto la parte del trato que le corresponde, deberá encontrar en su empresa la reciprocidad debida” (Ávila, 2017, p. 188). La organización, seleccionado el personal que como tal se supone, deberá enfocar sus esfuerzos en generar políticas que propicien un entorno adecuado para que este tipo de compromiso se pueda expresar.

“Aspectos como la satisfacción, el compromiso, la motivación...no son políticas de recursos humanos en sentido estricto, sino que estarían más en el ámbito de las consecuencias o resultados de las prácticas implantadas en la organización. De hecho, cuando se quieren gestionar estos temas, donde se tiene que incidir es en las políticas, por tanto, estos aspectos no lo son en sí mismas.” (Maella, 2010, p. 12)

La estrategia de RRHH de la organización, impacta, a través de sus políticas de dirección de personas, en la percepción que tienen los trabajadores de ellas, evocando un mayor o menor nivel de Compromiso Organizacional (ligazón afectiva) y consecuentes derivadas: rotación, absentismo, y rendimiento; compromiso que viene moderado por la concepción ética del trabajador, que puede decidir seguir empleándose a fondo aunque disminuya su ligazón afectiva, o incluso que esta disminuya como consecuencia de que no se sienta identificado con el patrón ético de su empresa.

Por todo lo apuntado, se está trabajando en dos publicaciones que permitirán: 
-Ampliar la base investigadora del impacto que tiene la percepción de los trabajadores de las políticas de RRHH en el Compromiso Organizacional, entendido este como ha quedado definido en la propuesta primera.

-Elaborar una propuesta de cuadro de mando, que informe de los índices relativos a la percepción de las políticas de dirección de personas, del nivel o grado de compromiso, y del absentismo y de la rotación de los empleados de la organización, así como, de sus derivadas económicas en forma de coste, rendimiento, estructura de supervisión, y estructura de apalancamiento.

\section{CONCLUSIONES}

El objetivo de este trabajo ha sido proponer un modelo teórico del Compromiso Organizacional con una base empírica, que forma parte de la investigación realizada sobre un Modelo de Gestión del Compromiso Organizacional (Ávila, 2019), y se fundamenta en:

a) Un análisis factorial exploratorio del cual se extrajo un factor que se corresponde con la dimensión afectiva del mismo.

b) Un análisis factorial de segundo orden en el que se comprobó que dicha dimensión seguía sin desdoblarse, y que, por tanto, avala la propuesta de un constructo afectivo de una sola dimensión.

c) Los resultados obtenidos fueron confirmados por un análisis factorial confirmatorio.

Lo que permite clarificar la naturaleza y dimensiones de este tipo de compromiso.

En base a lo anterior, y para dar respuesta a dicho objetivo, se ha establecido:

a) Un marco filosófico de referencia desde una doble perspectiva: la del trabajador, y la de la organización en función del estilo de liderazgo que emplea su dirección.

b) Discutido, de acuerdo con el marco filosófico anterior, la propuesta tridimensional de Meyer y Allen por entender que no todas sus dimensiones son fuente de este tipo de compromiso.

c) Y propuesto una nueva definición y modelo.

Como consecuencia, se han llegado a las siguientes conclusiones:

-La única fuente de Compromiso Organizacional es el compromiso afectivo.

El trabajador persigue hacer aquello que le gusta con la intención de alcanzar sus objetivos y los de la empresa, de lo que se deriva que más que un estado psicológico (concepción reactiva), es una ligazón afectiva que le une con la organización (naturaleza proactiva), en la que este persigue lo mejor para la empresa y para él mismo. La ligazón se establece con una actividad y empresa concretas, por lo que el trabajador se podrá manifestar comprometido con una organización y falto de compromiso con otra. De ahí que se proponga un modelo unidimensional de compromiso de naturaleza afectiva. En este caso, se afirmará que el trabajador “está" comprometido con la empresa.

- Los ítems de las escalas que miden el compromiso afectivo de los empleados deben informar de la proactividad del trabajador en la consecución del logro organizativo y no de la satisfacción evocada por la empresa.

Medir el estado anímico del empleado con preguntas como las de la escala afectiva de Meyer y Allen, no informa de su disposición por conseguir los objetivos de la empresa. Los ítems de la escala afectiva, se debieran redactar en atención a informar de la proactividad que muestra el individuo en la consecución del logro organizativo, y no de la satisfacción laboral que le genera la empresa. El Compromiso Organizacional proporciona una explicación más completa que la satisfacción laboral en aras a justificar los comportamientos extra-role de los 
empleados (Eldor y Harpaz, 2015). Las escalas de medida del compromiso afectivo debieran informar de lo que "hace" el trabajador por alcanzar los objetivos organizacionales, y no de lo que "siente" este aunque sea un sentimiento evocado por la empresa.

-La componente normativa no es una componente de Compromiso Organizacional.

Lo normativo se refiere al compromiso que manifiesta un individuo con sus particulares creencias de lo que es correcto hacer; creencias, que estarán siempre presentes en él al margen de la organización en la que este se encuentre. En este caso, se afirmará que el trabajador “es” un individuo comprometido, de lo que se deriva que siéndolo siempre, podrá no estar comprometido con una organización y proyecto concretos; de ahí la diferencia entre lo afectivo: se está comprometido, y lo normativo: se es comprometido.

-La función de la componente normativa es moderar al compromiso afectivo.

Tal como ha quedado dicho, la componente normativa se refiere a un compromiso (de naturaleza racional) del empleado consigo mismo, con su concepción particular de lo que es correcto y obligado hacer, y no con una organización concreta. Al ser una forma de actuar, un estilo particular de hacer, su función es la de moderar su conducta emocional, de tal forma, que en ocasiones y aunque su ligazón afectiva sea baja, procurará un mayor esfuerzo, y en otras, será la falta de sintonía con lo ético de su organización la que provoque su declinar afectivo; de ahí que cuando los objetivos de la organización y del empleado estén alineados, se solapen los efectos de la componente afectiva y normativa (De Frutos et al., 1998; Jong-Wook et al., 1997)

- Las escalas afectivas deben eliminar los ítems que informen de actitudes de naturaleza ética.

Las escalas actuales de compromiso afectivo, y las propuestas futuras, debieran eliminar los ítems que informen de actitudes y comportamientos de racionalidad moral, que debieran quedar reservados para las escalas que informen del alineamiento ético que se da entre el individuo y su organización, y así, conocer la evolución de la dimensión moderadora de su compromiso afectivo.

-La dimensión de continuidad no es una componente del Compromiso Organizacional.

Y no lo es porque el trabajador solo se centra en su particular interés y no lo hace con el todo organizativo. Procurar lo mejor para la organización, implica comportamientos evocados por la motivación intrínseca (se está comprometido) y trascendente (se es comprometido) del trabajador, o por una sola de ellas, pero en ningún caso por el único deseo de velar por sus propios intereses. En este caso, se afirmará que el trabajador es una persona "interesada” puesto que solo piensa en su beneficio.

- Las escalas afectivas deben eliminar los ítems que informen del interés por continuar en la empresa.

Las escalas actuales de compromiso afectivo, y las propuestas futuras, debieran eliminar los ítems que informen de la intención de continuar en la empresa porque esta dimensión no es fuente de Compromiso Organizacional. Continuar o no, es una consecuencia del compromiso afectivo del trabajador y no una dimensión distinta de su Compromiso Organizacional. En la actualidad, permanecer ya no es sinónimo de estar comprometido, sino la consecuencia de quien sintiéndose ligado afectivamente con la organización procura lo mejor para ella.

El presente trabajo, propone un modelo y concepción del Compromiso Organizacional, que puede tener importantes implicaciones en futuras investigaciones sobre este tipo de compromiso, al dejarlo definido como un constructo unidimensional de actitud y naturaleza afectiva, que viene moderada por la concepción ética de lo que el trabajador tiene por correcto hacer. Modelo que resuelve el dilema de (Cohen, 2007; Jaros, 2007; Jong-Wook et al., 1997) al aclarar que el compromiso afectivo no es una dimensión más del Compromiso 
Organizacional sino su esencia misma, al igual que proponía Mercurio (2015), y sospechaban M. Dávila y Jiménez (2012), y en el que no cabe considerar, por no ser fuente de este tipo de compromiso, a las dimensiones de continuidad y normativa de la propuesta de Meyer y Allen.

\section{BIBLIOGRAFÍA}

Albrecht, S., \& Andreetta, M. (2011). The influence of empowering leadership, empowerment and engagement on affective commitment and turnover intentions in community health service workers: Test of a model. Leadership in Health Services, vol. 24, n 3, pp. 228237. https://doi.org/10.1108/17511871111151126.

Allen, N., \& Meyer, J. (1990). The measurement and antecedents of affective, continuance and normative commitment to the organization. Journal of Occupational Psychology, vol. 63, no 1, pp. 1-18. https://doi.org/10.1111/j.2044-8325.1990.tb00506.x.

Allport, G. (1943). The Ego in Contemporary Psychology. Psychological Review, vol. 50, $\mathrm{n}^{\circ} 5$, pp. 451-478. https://doi.org/10.1037/h0055375.

Apascaritei, P., \& Elvira, M. (2018). Agilidad Estratégica a Través del Capital Humano/ ST-nº 479, pp. 1-15. https://doi.org/10.15581/018.ST-479.

Arciniega, L. (2002). Compromiso organizacional México ¿Cómo hacer que la gente se ponga la camiseta ? Dirección Estratégica, $\mathrm{n}^{0} 11$, pp. 21-23.

Aristóteles. (2011). Ética a Nicómaco. Madrid: Tecnos.

Ariza, J., \& Morales, E. (1997). Flexibilidad y compromiso: cemento de las estructuras organizativas emergentes. Estudios Financieros, ${ }^{\circ} 175$, pp. 95-150.

Ashman, I., \& Winstanley, D. (2006). The ethics of organizational commitment. Business Ethics: A European Review, vol. 15, no 2, pp. 142-153. https://doi.org/10.1111/j.14678608.2006.00438.x.

Ávila, S. (2017). Desde la felicidad hacia el compromiso. Madrid: Pearson Eduación S.A.

Ávila, S. (2019). Modelo de Gestión del Compromiso Organizacional: Estudio aplicado a una Empresa de Servicios de Seguridad Privada en España. Universidad CEU San Pablo. Retrieved from https://www.educacion.gob.es/teseo/mostrarSeleccion.do

Ávila, S., \& Pascual, M. (2019). Propiedades psicométricas de un cuestionario para evaluar la percepción de los trabajadores de las políticas de recursos humanos y su compromiso organizacional. Methaodos. Revista de Ciencias Sociales, vol. 7, n ${ }^{\circ}$ 2, pp. 165-183. https://doi.org/http://dx.doi.org/10.17502/m.rcs.v7i2.258.

Baez-Santana, R. A., Zayas-Agüero, P. M., Velázquez-Zaldívar, R., \& Lao-León, Y. O. (2019). Modelo conceptual del compromiso organizacional en empresas cubanas / Conceptual model of organizational commitment in Cuban enterprises Modelo conceptual del compromiso organizacional en empresas cubanas Conceptual model of organizational commitment in C. Ingenieria Industrial, XXXVIII, n 3 , pp. 14-23.

Basak, A., \& Vandenberghe, C. (2016). Organizational and career-oriented commitment and employee development behaviors. Journal of Managerial Psychology, vol. 31, n 5, pp. 930-945. https://doi.org/10.1108/JMP-04-2015-0157.

Bass, B. (1999). Two Decades of Research and Development in Transformational Leadership. Psychology Press Ltd European Journal of Work and Organizational Psychology, vol. 8, n 1, pp. 9-32. https://doi.org/10.1080/135943299398410.

Bauman, Z. (2004). Modernidad líquida. Buenos Aires: Fondo de Cultura Económica de Argentina.

Becker, H. (1960). Notes On the Concept of Commitment. The American Journal of Sociology, vol. 66, n 1, pp. 32-40. https://doi.org/10.1086/222820. 
Bergman, M. (2006). The relationship between affective and normative commitment: Review and research agenda. Journal of Organizational Behavior, vol. 27, n 5, pp. 645-663. https://doi.org/10.1002/job.372.

Bermejo, J. C., Villacieros, M., \& Magaña, M. (2014). Perfil, motivación, satisfacción y compromiso de un voluntariado de acompañamiento en duelo. Propiedades psicométricas de los cuestionarios Organizational Commitment Questionnarie y Job Diagnostic Survey. Medicina Paliativa, $\mathrm{n}^{\mathrm{o}}$ 24, pp. 4-13. https://doi.org/10.1016/j.medipa.2014.05.003.

Branham, L. (2005). The 7 Hidden Reasons Employees Leave: How to Recognize the Subtle Signs and Act Before It's Too Late. New York: American Management Association.

Buchanan, B. (1974). Building Organizational Commitment: The Socialization of Managers in Work Organizations. Administrative Science Quarterly, vol. 19, n 4, pp. 533-546. https://doi.org/10.2307/2391809.

Cappelli, P. (2000). The new deal at work. Chicago-Kent Law Review, vol. 76, nº 2, pp. 11691193.

Cardona, P. (2000). Liderazgo relacional (Documento de investigación IESE Business School $\mathrm{n}^{\circ} 412$.

Carmeli, A., \& Freund, A. (2004). Work Commitment, Job Satisfaction, and Job Performance: an Empirical Investigation. International Journal of Organization Theory and Behavior, vol. 6, n 4, pp. 289309.

Cernas, D. A., \& Nava, R. M. (2019). Compromiso organizacional y promedio escolar en estudiantes de maestría: el efecto moderador de las tendencias alocéntricas e idiocéntricas. Revista Electrónica de Investigación Educativa, vol. 21, nº e26, pp. 1-10. https://doi.org/10.24320/redie.2019.21.e26.2122.

Chang, C.-H. (2006). "I" is to continuance as "We" is to affective: the relevance of the selfconcept for organizational commitment. Journal of Organizational Behavior, vol. 27, $\mathrm{n}^{\circ}$ 5, pp. 549-570. https://doi.org/10.1002/job.364.

Chiavenato, I. (2009). Gestión del talento humano. México, D.F.: McGraw-Hill.

Chinchilla, N. (2000). Ties of Belonging and Organizational Commitment (Nota Ténica IESE Business School No. FHN-326-E).

Chughtai, A. (2013). Linking affective commitment to supervisor to work outcomes. Journal of Managerial Psychology, vol. 28, nº 6, pp. 606-627. https://doi.org/10.1108/JMP-092011-0050.

Cohen, A. (2003). Multiple Commitments in the Workplace: An Integrative Approach. The Academy of Management Review. Psychology Press.

Cohen, A. (2007). Commitment before and after: An evaluation and reconceptualization of organizational commitment. Human Resource Management Review, vol. 17, n 3, pp. 336-354. https://doi.org/10.1016/j.hrmr.2007.05.001.

Csikszentmihalyi, M. (2007). Fluir (Flow). Una psicología de la felicidad. Barcelona: Kairós.

Dávila, C., \& Jiménez, G. (2014). Sentido de pertenencia y compromiso organizacional: predicción del bienestar. Revista de Psicología, vol. 32, $\mathrm{n}^{\circ}$ 2, pp. 272-302. https://doi.org/10.1174/021347406778538230.

Dávila, M., \& Jiménez, G. (2012). Organizational Identification and Commitment: Correlates of Sense of Belonging and Affective Commitment. The Spanish Journal of Psychology, vol. 15, nº 1, pp. 244-255. https://doi.org/10.5209/rev_SJOP.2012.v15.n1.37316.

De Frutos, B., Ruiz, M., \& San Martín, R. (1998). Análisis factorial confirmatorio de las dimensiones. Psicológica, no 19, pp. 345-366. https://doi.org/10.1157/13057542.

Eldor, L., \& Harpaz, I. (2015). A process model of employee engagement: The learning climate and its relationship with extra-role performance behaviors. Journal of Organizational Behavior, vol. 37, n 2, pp. 213-235. https://doi.org/10.1002/job.2037. 
Farrell, D., \& Rusbult, C. (1981). Exchange Variables As Predictors of Job Satisfaction, Job Commitment, and Turnover: The Impact of Rewards, Costs, Alternatives, and Investments. Organizational Behavior and Human Performance, vol. 28, nº 1, pp. 7895. https://doi.org/10.1016/0030-5073(81)90016-7.

García Parra, A. T. (2004). Una nueva teoría de motivación: El modelo antropológico de Juan Antonio Pérez López. Revista Puertorriqueña de Psicología, vol. 15, nº 1, pp. 123-163. Retrieved from https://dialnet.unirioja.es/servlet/articulo?codigo=4896080.

Gavilán, D., Fernández-Lores, S., María, A., \& de Andrés, E. (2014). Medir el compromiso, el nuevo must de RR.HH.

George, D., \& Mallery, P. (2003). SPSS for Windows step by step: A simple guide and reference. 11.0" $\left(4^{\mathrm{a}}\right)$. Boston: Allyn \& Bacon.

Goleman, D. (1999). La práctica de la inteligencia emocional. Barcelona: Kairos.

Gómez-Llera, G. (1990). Los recursos humanos en las organizaciones (Nota Técnica IESE Business School No. FHN-215. Rev 1/91). Barcelona.

González-Cruz, T., \& Guillén, M. (2008). Organizational Commitment: A Proposal for a Wider Ethical Conceptualization of 'Normative Commitment.' Journal of Business Ethics, vol. 78, n 3, pp. 401-414. https://doi.org/10.1007/s10551-006-9333-9.

González, F., López-Guzmán, T., \& Sánchez, S. (2014). Job satisfaction and organizational commitment in human resources in the hotel sector of Cordoba (Spain): Influence of the type of contract and working day. Intangible Capital, vol. 10, no 1, pp. 189-211. https://doi.org/10.3926/ic.489.

González, F., Sánchez, S., \& López, T. (2014). Influencia de variables personales en el compromiso organizativo de los empleados del sector hotelero. Revista Galega de Economía, vol. 23, $\mathrm{n}^{\circ}$ 2, pp. 27-46.

Hansen, A., Byrne, Z., \& Kiersch, C. (2014). How interpersonal leadership relates to employee engagement. Journal of Managerial Psychology, vol. 29, $\mathrm{n}^{\circ}$ 8, pp. 953-972. https://doi.org/10.1108/JMP-11-2012-0343.

Jaros, S. (2007). Meyer and Allen Model of Organizational Commitment : Measurement Issues. The Icfai Journal of Organizational Behavior, vol. 6, $\mathrm{n}^{\circ}$ 4, pp. 7-26. https://doi.org/10.1348/096317906X118685.

Jay, S. (2004). La falsa medida del hombre. Barcelona: Crítica.

Jong-Wook, K., Price, J., \& Mueller, C. (1997). Assessment of Meyer and Allen's ThreeComponent Model of Organizational Commitment in South Korea. [Report]. Journal of Applied Psychology December 1997; vol. 82, $\mathrm{n}^{\circ} \quad 6$, pp. 961-973. https://doi.org/10.1037//0021-9010.82.6.961.

Juaneda, E., \& González, L. (2007). Definición, antecedentes y consecuencias del compromiso organizativo. Conocimiento, Innovación y Emprendedores: Camino Al Futuro, pp. 3590-3609.

Kam, C., Morin, A., Meyer, J., \& Topolnytsky, L. (2016). Are Commitment Profiles Stable and Predictable? A Latent Transition Analysis. Journal of Management, vol. 42, $\mathrm{n}^{\circ}$ 6, pp. 1462-1490. https://doi.org/10.1177/0149206313503010.

Kanter, R. (1968). Commitment and Social Organization: A Study of Commitment Mechanisms in Utopian Communities. American Sociological Review, vol. 33, n ${ }^{\circ}$, pp. 499-517. https://doi.org/10.2307/2092438.

Kehoe, R., \& Wright, P. (2010). The Impact of High Performance HR Practices on Employees' Attitudes and Behaviors. Journal of Management - J MANAGE, vol. 36, $\mathrm{n}^{\circ}$ 2, pp. 366391. https://doi.org/10.1177/0149206310365901.

Klein, H. (2016). Commitment in organizational contexts: Introdyuction to the special issue. Journal of Organizational Behavior, $\mathrm{n}^{\circ}$ 37, pp. 489-493. https://doi.org/10.1002/job. 
Luchak, A., \& Gellatly, I. (2007). A comparison of linear and nonlinear relations between organizational commitment and work outcomes. [References]. Journal of Applied Psychology, vol. 92, no 3, pp. 786-793. https://doi.org/10.1037/0021-9010.92.3.786.

Maella, P. (2010). Occasional Paper ¿ Cómo establecer una estrategia de recursos humanos eficaz? (Ocasional Paper IESE Business School No. OP-181).

Mercurio, Z. (2015). Affective Commitment as a Core Essence of Organizational Commitment: An Integrative Literature Review. Human Resource Development Review, vol. 14, no 4, pp. 389-414. https://doi.org/10.1177/1534484315603612.

Meyer, J., \& Allen, N. (1984). Testing the "side-bet theory" of organizational commitment: Some methodological considerations. Journal of Applied Psychology, vol. 69, n 3, pp. 372-378. https://doi.org/10.1037//0021-9010.69.3.372.

Meyer, J., \& Allen, N. (1997). Commitment in the Workplace: Theory, Research, and Application. Thousand Oaks: Sage.

Meyer, J., \& Herscovitch, L. (2001). Commitment in the Workplace: Toward a General Model. Human Resource Management Review, vol. 11, $\mathrm{n}^{\mathrm{o}}$ 3, pp. 299-326. https://doi.org/10.1016/S1053-4822(00)00053-X.

Meyer, J., \& Morin, A. (2016). A person-centered approach to commitment research: Theory, research, and methodology. Journal of Organizational Behavior, vol. 37, n 4, pp. 584 612. https://doi.org/10.1002/job.2085.

Meyer, J., Stanley, D., Herscovitch, L., \& Topolnytsky, L. (2002). Affective, continuance, and normative commitment to the organization: A meta-analysis of antecedents, correlates, and consequences. Journal of Vocational Behavior, vol. 61, $\mathrm{n}^{0}$ 1, pp. 20-52. https://doi.org/10.1006/jvbe.2001.1842.

Morrow, P. (2011). Managing organizational commitment: Insights from longitudinal research. Journal of Vocational Behavior, vol. 79, $\mathrm{n}^{\circ}$ 1, pp. 18-35. https://doi.org/10.1016/j.jvb.2010.12.008.

Mowday, R., Porter, L., \& Dubin, R. (1974). Unit Performance, Situational Factors, and Employee Attitudes in Spatially Separated Work Units. Organizational Behavior and Human Performance, vol. 12, $\mathrm{n}^{\mathrm{o}}$ 2, pp. 231-248. https://doi.org/10.1016/00305073(74)90048-8.

Mowday, R., Porter, L., \& Steers, R. (1982). Employee-Organization Linkages: the psychology of commitment, absenteeism, and turnover. New York: Academic Press.

Mowday, R., Steers, R., \& Porter, L. (1979). The Measurement of Organizational Commitment. Vocational Behavior, $\mathrm{n}^{\circ}$ 14, pp. 224-247. https://doi.org/10.1016/0001-8791(79)900721.

Neves, T., Graveto, J., Rodrigues, V., Marôco, J., \& Parreira, P. (2018). Organizational commitment, psychometric qualities and invariance of the Meyer and Allen Questionnaire for Portuguese Nurses. Revista Latino-Americana de Enfermagem, $\mathrm{n}^{\circ}$ 26(e3021), pp. 1-11. https://doi.org/10.1590/1518-8345.2407.3021.

Newstrom, J. (2011). Comportamiento humano en el trabajo (13th ed.). McGraw-Hill Interamericana de España.

Nunnally, J. (1978). Psychometric theory (2a). Ann Arbor, Michigan: McGraw-Hill.

O’Reilly, C., \& Chatman, J. (1986). Organizational Commitment and Psychological Attachment: The Effects of Compliance, Identification, and Internalization on Prosocial Behavior. Journal of Applied Psychology, vol. 71, $\mathrm{n}^{\circ}$ 3, pp. 492-499. https://doi.org/10.1037//0021-9010.71.3.492.

Pare, G., \& Tremblay, M. (2007). The Influence of High-Involvement Human Resources Practices, Procedural Justice, Organizational Commitment, and Citizenship Behaviors on Information Technology Professionals’ Turnover Intentions. Group \& Organization Management, vol. 32, nº 3, pp. 326. https://doi.org/10.1177/1059601106286875. 
Pérez López, J. A. (1985a). La dirección de empresas y el liderazgo (0-486-002 No. FHN-167). Barcelona.

Pérez López, J. A. (1985b). Las motivaciones humanas (0-484-011 No. FHN-161). Barcelona.

Poon, J. (2013). Relationships among perceived career support, affective commitment, and work engagement. International Journal of Psychology, vol. 48, $\mathrm{n}^{\circ}$ 6, pp. 1148-1155. https://doi.org/10.1080/00207594.2013.768768.

Porter, L., Steers, R., \& Monday, R. (2005). Do employee attitudes towards organizations matter? The study of employee commitment to organizations. In Great minds in management : the process of theory development, pp. 171-189. Oxford: Oxford Univ. Press.

Porter, L., Steers, R., Mowday, R., \& Boulian, P. (1974). Organizational commitment, job satisfaction, and turnover among psychiatric technicians. Journal of Applied Psychology, vol. 59, $\mathrm{n}^{\circ}$ 5, pp. 603-609. https://doi.org/10.1037/h0037335.

Randall, D., \& Cote, J. (1991). Interrelationships of Work Commitment Constructs. Work and $\begin{array}{llllll}\text { Occupations, } & \text { vol. } \quad 18, \quad \mathrm{n}^{0} & 2, & \text { pp. }\end{array}$ https://doi.org/10.1177/0730888491018002004.

Robbins, S., \& Judge, T. (2009). Comportamiento organizacional. Naucalpan de Juárez: Prentice Hall.

Ruiz de Alba, J. L. (2013). El Compromiso Organizacional: Un Valor Personal Y Empresarial En El Marketing Interno. Revista de Estudios Empresariales. Segunda Época., $\mathrm{n}^{\circ}$ 1, pp. 67-86.

Scholarios, D., \& Marks, A. (2004). Work-life balance and the software worker. Human Resource Management Journal, vol. 14, n 2, pp. 54-74. https://doi.org/10.1111/j.17488583.2004.tb00119.x.

Serra, P., Ponce, M. J., Laura, L., González, L., \& García, X. Introducción II - Regresión lineal simple y múltiple (parte 2 de 5) (2014). Valencia. Retrieved from https://www.youtube.com/watch?v=KkcPHTVUCMc\&list=PLWzyFeBMG81xPCE2 UO_pTxbHjOl-8e6-f

Sheldon, M. (1971). Investments and Involvements as Mechanisms Producing Commitment to the Organization. Administrative Science Quarterly, vol. 16, $\mathrm{n}^{\circ}$ 2, pp. 143-150. https://doi.org/10.2307/2391824.

Simo, P., Sallan, J., \& Rajadell, M. (2013). Compromiso Organizativo y Empresa Familiar: Estado del arte. In Nuevas investigaciones sobre la empresa familiar en España, pp. 5568. https://doi.org/10.3926/oms.175.

Solinger, O., Van Olffen, W., \& Roe, R. (2008). Beyond the Three-Component Model of Organizational Commitment. Journal of Applied Psychology, vol. 93, n 1, pp. 70-83. https://doi.org/10.1037/0021-9010.93.1.70.

Stazyk, E., Pandey, S., \& Wright, B. (2011). Understanding Affective Organizational Commitment: The Importance of Institutional Context. American Review of Public Administration, vol. 41, $\mathrm{n}^{\circ}$ 6, pp. 603-624. https://doi.org/10.1177/0275074011398119.

Sun, L.-Y., Aryee, S., \& Law, K. (2007). High-performance human resource practices, citizenship behavior, and organizational performance: A relational perspective. Academy of Management Journal, vol. 50, $\mathrm{n}^{\mathrm{0}}$ 3, pp. 558-577. https://doi.org/10.5465/AMJ.2007.25525821.

Tuddenham, R. (1962). The nature and measurement ofintelligence. In L. Postman (Ed.), Psychology in the Making, pp. 469-525. Nueva York: Alfred A. Knopf.

Vecina, M. L., \& Chacón, F. (2013). Is engagement different from satisfaction and organizational commitment? Relations with intention to remain, psychological wellbeing and perceived physical health in volunteers. Anales de Psicología, vol. 29, $\mathrm{n}^{\circ} 1$, pp. 225-232. https://doi.org/10.6018/analesps.29.1.161861. 
Whitener, E. M. (2001). Do "high commitment" human resource practices affect employee commitment?: A cross-level analysis using hierarchical linear modeling. Journal of Management, vol. 27, $\mathrm{n}^{\circ}$ 5, pp. 515-535. https://doi.org/10.1177/014920630102700502.

Yalabik, Z. Y., Popaitoon, P., Chowne, J., \& Rayton, B. (2013). Work engagement as a mediator between employee attitudes and outcomes. International Journal of Human Resource Management, vol. 24, $\mathrm{n}^{\mathrm{o}}$ 14, pp. 2799-2823. https://doi.org/10.1080/09585192.2013.763844.

Young, B. S., Worchel, S., \& Woehr, D. J. (1998). Organizational Commitment among Public Service Employees. Public Personnel Management, vol. 27, $\mathrm{n}^{\circ}$ 3, pp. 339-348. https://doi.org/10.1177/009102609802700304. 
Anexo 1

Dimensión Afectiva

- Yo estaría muy feliz de pasar el resto de mi carrera en esta organización.

- Disfruto discutiendo de mi organización con gente ajena a ella.

- Realmente percibo los problemas de la organización como si fuesen míos.

- Creo que me resultaría indiferente sentirme ligado con otra empresa distinta de la actual "R".

- No siento a mi organización como parte de mi familia "R".

- No me siento emocionalmente ligado con esta organización "R”.

- Esta organización tiene un significado personal muy grande para mí.

- Yo no percibo un fuerte sentido de pertenencia con mi organización "R".

\section{Dimensión de Continuidad}

- No estoy preocupado de lo que pudiera suceder si renunciara a mi trabajo sin tener otra alternativa "R".

- Ahora, aunque quisiera, sería muy difícil para mí dejar mi organización.

- Si decidiera dejar la organización, mi vida se quedaría demasiado desestructurada.

- Ahora, no sería demasiado costoso para mí dejar mi organización "R".

- Actualmente, quedarse en la organización es más una necesidad que un deseo.

- Para considerar el abandono de esta organización siento que tengo muy pocas opciones "R".

- Una de las escasas consecuencias graves del abandono de esta organización sería la escasez de alternativas.

- Una de las principales razones por las que continúo trabajando para esta organización sería que dejarla requeriría un considerable sacrificio personal; en otra organización no podría igualar mis actuales beneficios generales.

\section{Dimensión Normativa}

- Creo que en la actualidad la gente cambia de empresa con demasiada frecuencia.

- No creo que una persona deba ser siempre leal a su empresa "R".

- Saltar de una organización a otra ya no me parece falto de ética "R".

- Una de las principales razones por las que continúo trabajando para esta organización es que creo que la lealtad es importante y por tanto siento la obligación moral de permanecer en ella.

- Aunque tuviera otra oferta de trabajo mejor en otro lugar no percibiría como correcto dejar mi organización.

- Me educaron en el valor de permanecer leal a una organización.

- Las cosas eran mejores en los días que la gente permanecía en una organización la mayor parte del tiempo de su vida laboral.

- No creo que ya sea relevante ser un hombre de empresa "R".

Fuente: (Allen \& Meyer, 1990, pp. 6-7) 